\title{
Team-based learning for psychiatry residents: a mixed methods study
}

\author{
Isabel McMullen ${ }^{1 *}$, Jonathan Cartledge ${ }^{2}$, Ruth Levine ${ }^{3}$ and Amy Iversen ${ }^{4}$
}

\begin{abstract}
Background: Team-based learning (TBL) is an effective teaching method for medical students. It improves knowledge acquisition and has benefits regarding learner engagement and teamwork skills. In medical education it is predominately used with undergraduates but has potential benefits for training clinicians. The aims of this study were to examine the impact of TBL in a sample of psychiatrists in terms of classroom engagement, attitudes towards teamwork, learner views and experiences of TBL.

Methods: Forty-four psychiatry residents participated in an Addictions Psychiatry TBL module. Mixed-methods were used for evaluation. Self-rated measures of classroom engagement (Classroom Engagement Survey, CES) were compared with conventional lectures, and attitudes regarding the value of teams (Value of Teams Scale, VTS) were compared before and after the module. Independent t-tests were used to compare 'lecture' CES scores with TBL CES scores and pre and post scores for the VTS. Feedback questionnaires were completed. Interviews were conducted with a subset of residents and transcripts analysed using thematic analysis.

Results: Twenty-eight residents completed post-course measures (response rate 63.6\%). Seven participants volunteered for qualitative interviews-one from each team. There was a significant difference in the mean CES score lectures compared to TBL $(p<0.001)$ but no difference was found in mean VTS score pre and post for either subscale $(p=0.519 ; p=0.809)$. All items on the feedback questionnaire were positively rated except two regarding session preparation. The qualitative analysis generated seven themes under four domains: 'Learning in teams', 'Impact on the individual learner', 'Relationship with the teacher' and 'Efficiency and effectiveness of the learning process'.
\end{abstract}

Conclusions: In this group of residents, TBL significantly improved learner-rated classroom engagement and seemed to promote interactivity between learners. TBL was generally well-received, although required learners to prepare for class which was difficult for some. TBL did not change these clinicians' views about teamwork.

Keywords: Instructional methods, Team-based learning, Continuing medical education, Residents, Psychiatry

\section{Background}

Team-based learning (TBL) is an educational method suited to teaching the problem-solving and teamwork skills required in medicine [1-3]. In TBL, learners acquire basic knowledge by completing pre-session assignments and during sessions work together in small teams to apply knowledge to real-life situations. TBL enables active learning to be achieved with large classes.

For medical students, TBL has produced equal [4] or superior [5-9] academic outcomes compared to didactic

\footnotetext{
* Correspondence: isabel.mcmullen@kcl.ac.uk

'Liaison Psychiatry, South London and Maudsley NHS Foundation Trust, Guys Hospital, Weston Street, London SE1 9RT, UK

Full list of author information is available at the end of the article
}

teaching. The educational impact is thought to be greatest for students in the lowest academic quartile $[10,11]$. TBL improves student participation and engagement during class, as rated by learners [12], objective observers [13-15], and faculty [16,17]. TBL also promotes teamwork skills [7]. TBL has improved medical student satisfaction in the USA $[7,9,17]$ and internationally [18-21]. Satisfaction increases as students and faculty become familiar with TBL: ratings increased each year as TBL became established [22,23].

While there is more limited experience of using TBL with clinicians, the data that exist suggest that TBL holds considerable promise for residency education. [12,24-26].

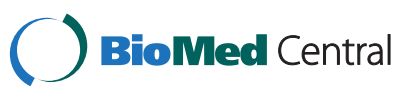


When compared to a lecture-based course for residents, TBL led to a similar increase in knowledge with greater participant engagement, although residents perceived TBL to have less educational value than lectures [14]. Using modified TBL to replace a lecture series led to improved knowledge scores with high ratings for perceived knowledge acquisition and enjoyment of interactive team discussions [26]. When primary care residents were given TBL "booster sessions" to learn the skill of alcohol screening and brief intervention, TBL was well received and reinforced their acquisition of a new clinical skill [24]. In a psychiatry residency training program focusing on the acquisition of psychotherapy skills, residents rated the presentation format as excellent, and specific comments about the TBL experience were overwhelmingly positive [25]. Since TBL moves beyond the basic acquisition of facts to focus on real life scenarios, it is an ideal didactic method for clinicians. As clinicians are used to solving patient problems and learning from them, TBL may be a natural way of learning for doctors in residency training.

The aims of this investigation were to determine whether, in a group of residents studying Addictions Psychiatry, TBL affected self-rated engagement and attitudes towards teamwork during a six-week teaching programme. We also aimed to assess doctors' experiences of TBL.

\section{Methods}

A mixed-methods observational study design was used. This was a pragmatic approach to evaluating the course. An alternative design such as a randomised controlled trial was rejected as it was not practical to run two parallel courses for the numbers of residents who were enrolled on the course.

\section{Setting}

Participants were Core Psychiatry Trainees (residents) on the largest psychiatry training programme in the UK (http://maudsleytraining.com). We modified an existing weekly training course consisting of lectures grouped into curriculum-themed modules. The Addictions Psychiatry module was selected to pilot TBL. It consisted of 12 hours, divided into six two-hour sessions. A TBL expert visited to give a lecture and workshop to train faculty, review written materials and co-facilitate a session.

\section{Recruitment}

All residents were sent information about the TBL module and evaluation prior to the start. There were no exclusion criteria: all residents attending the module were invited to participate in the evaluation. Sample size was limited by the numbers of residents attending the module, thus a sample size calculation was not undertaken.

\section{Structure of the module}

The orientation session included a demonstration of TBL, based on a presentation from the TBL Collaborative website [27]. During the session, residents were grouped into learning teams of 6-7 residents using the 'line-up' method [3]; learners were lined up according to previous Addictions Psychiatry experience and numbered into teams. This ensured that teams had approximately equal distribution of members with expertise in Addictions Psychiatry.

The TBL sessions ran from May to June 2012. The sessions were led by different subject experts each week, and co-facilitated by the researcher with TBL training. Each session followed the same format. Preparatory material was emailed the week before. In each session, participants sat the Individual Readiness Assurance Test (IRAT): 8-10 multiple choice questions with no access to materials or peer discussion. Following the IRAT, teams worked on the same questions together (Group Readiness Assurance Test, GRAT), using IF-AT (Immediate Feedback Assessment Technique) scratch cards to gain immediate feedback. The GRAT scores were posted at the front of the room. The expert clarified questions arising from the RAT. Teams then worked through Application Activities, reaching consensus on answers though intra-team discussion. When prompted by facilitators, all teams simultaneously revealed their answer by holding up a card marked with a letter to indicate their choice. The facilitators led inter-team discussions about the Applications. For examples of the materials used, see the 'Sample materials' in Appendix section.

\section{Measures}

\section{Learner-rated engagement}

The Classroom Engagement Survey (CES) [28] contains eight items measuring learner participation and enjoyment of class. It has been validated in a previous TBL study [8]. Items are scored on a 5-point Likert scale; maximum score range 5-40; higher scores indicate greater engagement. The questionnaire asks participants to rate the session that has just finished. For a comparison measurement, all participants who were present completed the CES immediately after a lecture from the previous module which was held just before the start of the preliminary TBL session. This was a typical lecture which was the standard method of teaching prior to the introduction of TBL. For the active measurement, participants completed it immediately after the final TBL session. This enabled comparison of engagement during a typical TBL session with that found during a typical lecture.

\section{Attitudes towards teamwork}

The Value of Teams survey (VTS) [29] measures 17 items in two dimensions: 'value of group work' and 'working with peers'. Items are scored on a 5-point Likert scale. 
Higher scores indicate perceptions of greater value of learning in teams (subscale scores range 6-30). The VTS was carried out at the same time points as the CES.

\section{Feedback questionnaires}

We created a 20-item questionnaire based on one used in previous TBL evaluations [30]. This was completed after the final TBL session. For each item, respondents used a 5-point Likert scale, scored from -2 to +2 . There were 20 items in total, with eight items making up each of the two factors: perceptions of teamwork and perceptions of TBL (factor scores ranged -16 to +16 ). Positive scores indicated favourable perceptions. The free text section of the questionnaire asked:

1. What did you like about TBL?

2. What did you not like about TBL?

3. Any other comments about TBL?

\section{Statistical analysis}

CES and VTS scores for each participant were entered on an Excel spreadsheet. SPSS was used to compare the variances of the samples and to calculate the difference in scores after the lecture and after the TBL session using a t-test. An independent t-test was used rather than a paired test as it could not be assumed that the same participants completed the pre and post questionnaires, due to varying participant attendance at the first and final sessions. As the questionnaires were completed anonymously, it could not be guaranteed that the samples were paired.

\section{Qualitative interviews}

Semi-structured interviews lasting 45 minutes to 1 hour were conducted with a volunteer from each team to enable the broadest sampling of views. Interviews were conducted by one researcher and were audio-recorded, then transcribed. Transcripts were stored in accordance with the Data Protection Act 1998. Transcripts were reviewed by the interviewee for accuracy and analysed using thematic analysis, which was chosen to allow for theoretical freedom during analysis.

\section{Ethical considerations}

Guidance was sought from the Psychiatry, Nursing and Midwifery Ethics Committee at King's College London, University College London Ethics Committee, and the South London and Maudsley NHS Foundation Trust/ Institute of Psychiatry Research and Development Office. All offices agreed in writing that the project was an evaluation project rather than research and thus did not require full ethical approval. Information sheets were given to all participants who gave written consent to participate.

\section{Results}

All 44 residents who attended the module participated in the evaluation. 22 (50\%) were female, 22 (50\%) were male. Three $(7 \%)$ had previous experience in Addictions Psychiatry. 26 residents completed initial measures; 28 completed post-course measures (response rate 63.6\%); 7/44 (16\%) were interviewed, one from each team.

\section{CES}

An independent t-test was used to compare the difference between the mean CES score following the didactic session and the CES score following the TBL module. An unequal variance t-test was used as the samples had different variances. A sensitivity analysis showed one outlier in the post group who was excluded and the t-test was run again, with no great difference in outcome. The mean CES score following the conventional didactic lecture was 25.5, the CES following the TBL session was 32.3, mean difference 6.8 (CI 3.4-10.1), $\mathrm{p}<0.001$.

\section{VTS}

Independent t-tests were used to compare pre and post scores on both subscales of the VTS: Value of Peers and Value of Group Work. For both subscales, the samples had equal variances and so an equal variance t-test was used. No significant difference was found in either subscale between the pre and post samples: Mean Value of Peers score pre $=24.8$, post $=24.3$, mean difference 0.45 (CI 0.93-1.83), $\mathrm{p}=0.519$; Mean Value of GroupWork score pre $=24.11$, post $=24.28$, mean difference 0.16 , (CI 1.191.52), $\mathrm{p}=0.809$.

\section{Feedback questionnaire}

Item scores ranged from -0.72 to +1.52 (Table 1 ). Eighteen (out of 20) items were positively scored, indicating an overall positive perception of TBL. The highest scoring items were: 'the ability to work in a team is necessary if I am to be successful as a psychiatrist' and 'I have a positive attitude about working with others in a team'. The two negatively scored items were: 'I found it easy to complete the presession reading' and 'I generally felt prepared for the IRAT'.

\section{Themes from interviews}

Thematic analysis revealed seven themes that were grouped under four domains:

\section{Learning in teams}

Learning knowledge in teams Interaction between team members consolidated previously learnt knowledge and enabled learning of new knowledge. The discussions led to deeper understanding and better retention:

'You're not just learning the answers, you're problem-solving, formulating arguments to justify 


\section{Table 1 Feedback questionnaire results}

\begin{tabular}{|c|c|}
\hline ITEM & MEAN \\
\hline $\begin{array}{l}\text { 1. TBL helped me increase my knowledge of addictions } \\
\text { psychiatry }\end{array}$ & 1.03 \\
\hline 2. I found it easy to complete the pre-session reading & -0.72 \\
\hline 3. I found the pre-session reading helpful & 0.28 \\
\hline $\begin{array}{l}\text { 4. Individual readiness assurance tests (IRAT) were useful } \\
\text { learning activities }\end{array}$ & 0.59 \\
\hline 5. I generally felt prepared for the IRAT & -0.10 \\
\hline $\begin{array}{l}\text { 6. The GRAT (group) discussions allowed me to improve } \\
\text { my understanding of concepts }\end{array}$ & 0.76 \\
\hline 7. The GRAT (group) discussions were useful learning activities & 0.97 \\
\hline 8. I learn better from TBL than from lectures & 0.45 \\
\hline 9. Solving problems in a group is an effective way to learn & 0.83 \\
\hline $\begin{array}{l}\text { 10. I learned useful additional information during the TBL } \\
\text { sessions }\end{array}$ & 1.03 \\
\hline 11. TBL helped me prepare for MRCPsych examinations & 0.03 \\
\hline 12. I have a positive attitude about working with others in a team & 1.24 \\
\hline $\begin{array}{l}\text { 13. The ability to work in a team is necessary if I am to be } \\
\text { successful as a psychiatrist }\end{array}$ & 1.52 \\
\hline $\begin{array}{l}\text { 14. Solving problems in a group is an effective way to practice } \\
\text { what I have learned }\end{array}$ & 1.14 \\
\hline 15. My team worked well together & 1.00 \\
\hline 16. I contributed meaningfully to the TBL discussions & 0.97 \\
\hline 17. Most students were attentive during TBL sessions & 0.86 \\
\hline 18. I paid attention most of the time during the TBL sessions & 0.86 \\
\hline $\begin{array}{l}\text { 19. The TBL format was helpful in developing my skills for } \\
\text { clinical practice }\end{array}$ & 0.59 \\
\hline $\begin{array}{l}\text { 20. There was mutual respect for other teammates' viewpoints } \\
\text { during TBL }\end{array}$ & 1.10 \\
\hline Total score for 'perception of TBL' factor & 5.14 \\
\hline Total score for 'perception of teamwork' factor & 7.76 \\
\hline
\end{tabular}

'Perception of TBL' items are in bold and 'perception of teamwork' items are in italics.

your position...the reasoning...means deeper learning...' [P2]

Individuals were motivated to study and concentrate as they felt responsible for their team's performance.

Learning about group dynamics The TBL process meant that teamwork skills were developed: communication skills, self-awareness, leadership, negotiation techniques, and respect for others. Teams actively managed interactions or let them naturally evolve. Teams became more cohesive during the module:

'We didn't know each other...now we're much more...interactive, challenging each other. It's great' [P5]
Social aspect of TBL Learning was 'fun', 'enjoyable'. This was enhanced by scratch-cards and competitive element:

'I love all that competitiveness. I really want to get the top score, win the prize' [P4]

TBL promoted interaction between different friendship and cultural groups:

'I would never have spoken to her if it hadn't been for us being in the same group' [P3]

Being part of a team meant that individuals were less fearful of answering questions in front of the class.

\section{Impact on the individual learner}

Impact on individuals' knowledge acquisition The preparatory reading structured learners' personal study, and the deadline was motivating for some. However there were differing views about whether the preparation was excessive. Participants found that completing the reading made the session more useful.

'It reactivates stuff I...know already...that makes that knowledge stick...more...you understand better, and then you remember it longer...' [P5]

The IRAT acted as a form of self-evaluation and was useful for individuals to assess how much they had learnt by preparing. The Applications were relevant to residents' clinical practice and were thought to improve clinical skills:

'The focus...on using the info you've learnt rather than just acquiring it... you come out ... a better doctor... it's so much more useful [than lectures]' [P6]

Applications encouraged reflection on clinical work which increased the material's relevance.

Impact on learning other skills/general qualities of TBL TBL promoted punctuality and engagement:

'because you're never doing the same thing for more than 15 minutes..., keeps your attention... impossible not to be...engaged in what you're doing... no-one's on their phones or email...so different' [P7]

Participants felt that the interactivity was more 'natural' than in lectures. It enabled learners to feel comfortable addressing the whole class. 


\section{Relationship with the teacher}

The increased interactivity led to a less formal relationship in which it was easier to ask questions:

\section{'it feels natural to ask questions... totally different to a lecture when it disturbs the flow if you ask a question' [P2]}

The RAT meant that teachers were aware of learners' baseline knowledge, which meant the session was pitched at correctly. Applications promoted discussion, enabled teachers to use clinical examples, and helped residents improve clinical decision-making skills.

\section{Efficiency and effectiveness of the learning process}

Participants viewed lectures as an efficient method of delivering a large amount of information and expressed concerns about whether TBL took longer to cover less material:

I'm not sure we're covering as much as we do in lectures... it's going in more, but it takes a long time to cover a few... concepts' [P3]

Learners found discussions helpful but were concerned they sometimes got 'distracted' by details. TBL was thought to be excellent at covering basic concepts, but learners felt that it was less effective at conveying advanced material and did not permit experts to present their latest research.

\section{Discussion}

These findings show that for this group of psychiatry residents, TBL led to a significant improvement in classroom engagement compared to learning via conventional lectures. However residents demonstrated no change in attitudes regarding the value of teams as measured by the VTS.

Does classroom engagement matter? A meta-analysis of the effectiveness of Continuing Medical Education (CME) found that lectures had no impact on clinician performance or patient outcomes, even though they may increase knowledge short-term [31]. However, interactive teaching had a small effect on professional performance and on occasion, healthcare outcomes, i.e. a positive impact on patient care. It has been suggested that physicians get most from CME if their learning is self-directed and derived from true-life clinical settings [32]-difficult to achieve in a lecture-based programme, but more realistic with TBL. Further, evidence suggests that bored learners learn less deeply [33], and that learners in a positive mood have improved recall [34] and working memory for words [35]. If we want learners to learn and retain more, increasing engagement will help.
Participants' ratings of the value of teams did not change during the module. This was unexpected as student studies showed that TBL caused improvement in individuals' appreciation of teamwork. Potentially this group of doctors were more aware of the advantages of learning in teams as a result of working in teams, as compared to students. For junior psychiatrists who work particularly closely with multidisciplinary teams [36], appreciation for the value of teamwork is especially relevant.

The qualitative data and questionnaire results show that participants held generally positive views about TBL. However there were two items with a mean negative score, both regarding pre-class preparation. Participants reported difficulty finding time to prepare because of conflicting demands from professional or personal commitments. Similar problems have been reported by others using TBL for residents [37]. These researchers asked residents to complete the preparatory reading and IRAT before class. Although attendance, satisfaction, and knowledge outcomes were good, only a third of residents completed the IRAT, suggesting that excluding it from class-time was not successful.

A challenge remains for those using TBL with residents: incentivizing residents to complete preparatory work may be more difficult than incentivizing students, who are largely motivated by grades. It is possible that our readings were too long, and may have been more acceptable to the residents if we had been more judicious when choosing pre-class preparation. Alternatively, we might have increased incentives for completing it if we had increased the rewards for doing well on IRATs and GRATs.

It may be useful for clinical teachers to know what aspects of TBL were thought to be the most effective, so that they may use these elements, even if they do not have time to carry out a complete TBL session. From the qualitative results, residents stated that the opportunity to work through real-life clinical scenarios with peers and an expert was the most beneficial aspect of TBL.

An important research question is to discover whether TBL produces more clinically competent residents than those trained by traditional courses. These results indicate that residents felt that TBL helped clinically, but this does not necessarily translate into improved performance.

\section{Limitations}

The lack of exclusion criteria meant that the sample was as broad and representative as possible of this population. Nonetheless, participants were recruited from one year of one training programme in psychiatry and therefore the results may have limited generalizability. The selection of one module meant that residents only received TBL for one topic area, from one group of faculty. Views held 
about the topic may have influenced views about TBL. Repeating the measures when TBL is used to teach other modules would enable comparison to ensure that attitudes were not topic-specific.

The measures were self-rated and subjective. An objective observation tool [15] was considered for measuring classroom engagement, but was rejected due to resource implications and concern that observers might disrupt sessions. The CES comparison also asked participants to compare a typical lecture with a typical TBL session. It may have been that the two sessions selected were not typical of lectures or TBL.

\section{Conclusions}

TBL led to improvement in learner-rated classroom engagement in this sample of residents. Greater classroom engagement may lead to greater learning and interactivity, which has been shown to improved clinical outcomes for patients. This study also shows that TBL was generally well-received, although required learners to prepare for class, something which was difficult for our busy clinicians to accept. In this sample, residents' views about teamwork were not altered by TBL which was different than the effect on students, however this may be because of a pre-existing high levels of appreciation of the value of teams in this sample.

\section{Appendix}

Sample materials

\section{Example of a RAT question}

Which of the following is an example of classical conditioning with regards addiction behaviour?

a. A heroin-dependent man develops heroin cravings when he sees a needle, spoon and syringe*

b. A group of friends who take heroin together socially and have done so from a young age

c. A heroin-dependent man who uses heroin because it acts to alleviate the symptoms of withdrawal

d. A heroin-dependent man who uses heroin because it causes a euphoric state

e. A man who uses heroin to relax because his father and brothers do so

\section{Example of an application activity}

A 24 year old man is remanded to prison. On assessment he reports injecting $1 \mathrm{~g}$ of heroin a day, smoking 2 rocks of crack cocaine a day, taking $20 \mathrm{mg}$ of illicit diazepam a day and drinking 6 cans of $9 \%$ beer every day. He is requesting opioid substitution treatment (OST) and an alcohol detoxification.
1.1 What single piece of information from the history would be most useful to help you decide whether to prescribe OST or not?

A) Time/amount of last drug use

B) Whether he was on OST in the community

C) Known drug allergies

D) Whether he currently feels he is suffering from opioid withdrawal symptoms

E) Past medical history

He tells you he last used over 24 hours ago and reports significant subjective opioid withdrawal symptoms. You carry out a physical examination.

1.2 Which of the following sets of findings would make you most likely to prescribe OST?

A) Tremor, sweating, dilated pupils, track marks

B) Drowsiness, heart rate $64 \mathrm{bpm}$, constricted pupils, track marks

C) Hypertension, agitation, sweating, tremor

D) Low weight, sweating, heart rate $72 \mathrm{bpm}$, tremor

E) Dilated pupils, heart rate $92 \mathrm{bpm}$, hypertension, sweating

You determine that he is in opioid withdrawal and you decide to prescribe OST. What would be the most appropriate investigation to support your decision?
A) Blood alcohol concentration
B) Urine drug screen
C) Hair strand testing
D) Saliva swab test
E) Blood screen (including LFTs)

Considering his alcohol use, he tells you that he drinks six cans of $9 \%$ abv beer every day. He reports that this has increased over the past six months since he was last in prison, but he no longer feels intoxicated after drinking. $\mathrm{He}$ is unaware of any health problems as a result of his alcohol consumption and denies "needing" to have a drink, or any physiological symptoms of alcohol withdrawal.

1.3 What is the best management of his alcohol use?

A) 5-day chlordiazepoxide reducing regime (starting at $20 \mathrm{mg}$ qds)

B) Monitoring of observations but no medication

C) Chlordiazepoxide prn

D) No treatment required

E) 3-day chlordiazopoxide reducing regime (starting at $10 \mathrm{mg}$ qds)

You decide to commence a chlordiazepoxide reducing regime and prescribe $20 \mathrm{mg}$ qds. He is also started on methadone $30 \mathrm{mg}$ and given a dose. The following 
morning you are asked to review the man. He is drowsy but rousable, with constricted pupils, and a heart rate of $58 \mathrm{bpm}$.

1.4 What is your best immediate course of action?

A) Stop the chlordiazepoxide

B) Administer naloxone intramuscularly

C) Move to medical wing for physical observation monitoring

D) Omit the next dose of methadone

E) Reduce the next dose of methadone to $20 \mathrm{mg}$

\section{Abbreviations}

TBL: Team-based learning; CES: Classroom engagement scale; VTS: Value of teams survey; CT: Core trainee (in psychiatry); CME: Continuing medical education.

\section{Competing interests}

The authors report no competing interests.

\section{Authors' contributions}

$\mathrm{IM}$ and $\mathrm{Al}$ conceived of the module and of the study. IM, AI and RL reviewed the materials for the module. IM, JC and AI designed the study. IM collected and analysed the data, and drafted the manuscript. All authors reviewed and approved the final manuscript.

\section{Authors' information}

Isabel McMullen is a Specialist Registrar in Liaison Psychiatry at Guys Hospital, South London and Maudsley NHS Foundation Trust.

Jonathan Cartledge is the director of the Royal College of Physicians/

University College London MSc, diploma and postgraduate certificate in

Medical Education. He is a senior lecturer in Medical Education at UCL, and a

consultant HIV physician at the Mortimer Market Centre.

Ruth E. Levine is the Clarence Ross Miller Professor of Psychiatry for the Department of Psychiatry and Behavioral Sciences and the Assistant Dean of Clinical Education at the University of Texas Medical Branch in Galveston, Texas.

Amy Iversen is a Consultant Liaison Psychiatrist and a Senior Lecturer in Medical Education at the Institute of Psychiatry, UK.

\section{Acknowledgements}

We thank the Maudsley Charity who funded this work, and Hannah Sallis from the Institute of Psychiatry Department of Biostatistics for her help with analysing the data.

We thank all the Addictions Psychiatry experts who taught on the TBL module, in particular Dr Emily Finch, and the residents who completed the evaluations.

\section{Author details}

${ }^{1}$ Liaison Psychiatry, South London and Maudsley NHS Foundation Trust, Guys Hospital, Weston Street, London SE1 9RT, UK. ${ }^{2}$ Academic Centre for Medical Education, University College London, Gower Street, London WC1E 6BT, UK. ${ }^{3}$ Department of Psychiatry and Behavioral Sciences, and Clinical Education, University of Texas Medical Branch, Galveston, TX 77555, USA. ${ }^{4}$ Institute of Psychiatry, Weston Education Centre, Cutcombe Road, London SE5 9RJ, UK.

Received: 20 February 2013 Accepted: 6 September 2013

Published: 11 September 2013

\section{References}

1. Hyrnchak P, Batty H: The educational theory basis of team-based learning. Med Teacher 2012, 34:796-801.

2. Searle NS, Haidet P, Kelly PA, Schneider VF, Seidel CL, Richards BF: Team learning in medical education: initial experiences at ten institutions. Acad Med 2003, 78(Suppl 10):S55-S58.

3. Parmelee DX, Michaelsen LK, Cook S, Hudes PD: Team-based learning: a practical guide: AMEE guide No. 65. Med Teacher 2012, 34:275-287.
4. Nieder GL, Parmelee DX, Stolfi A, Hudes PD: Team-based learning in a medical gross anatomy and embryology course. Clin Anat 2005, 18(1):56-63.

5. Thomas PA, Bowen CW: A controlled trial of team-based learning in an ambulatory medicine clerkship for medical students. Teach Learn Med 2011, 23(1):31-36

6. Vasan NS, DeFouw DO, Holland BK: Modified use of team-based learning for effective delivery of medical gross anatomy and embryology. Anat Sci Educ 2008, 1:3-9.

7. Vasan NS, DeFouw D: Team learning in a medical gross anatomy course. Med Educ 2005, 39:524

8. Levine RE, O'Boyle M, Haidet P, Lynn DH, Stone MM, Wolf DV, Paniagua FA: Transforming a clinical clerkship with team learning. Teach Learn Med 2004, 16:270-275.

9. Mcinerney MJ, Fink LD: Team-based learning enhances long-term retention and critical thinking in an undergraduate microbial physiology course. Microbiol Educ 2003, 4(1):3-12

10. Koles P, Nelson S, Stolfi A, Parmelee DA, DeStephen D: Active learning in a year 2 pathology curriculum. Med Educ 2005, 39:1045-1055.

11. Koles PG, Stolfi A, Borges NJ, Nelson S, Parmelee DX: The impact of teambased learning on medical Students' academic performance. Acad Med 2010, 85(11):1739-1745.

12. Haidet P, O'Malley KJ, Richards BF: An initial experience with team learning in medical education. Acad Med 2002, 77:40-44.

13. Hunt DP, Haidet $P$, Coverdale $J H$, Richards B: The effect of using team learning in an evidence-based medicine course for medical students. Teach Learn Med 2003, 15(2):131-139.

14. Haidet P, Morgan RO, O'Malley K, Moran BJ, Richards BF: A controlled trial of active versus passive learning strategies in a large group setting. Adv Health Sci Educ 2004, 9:15-27.

15. Kelly PA, Haidet P, Schneider V, Searle N, Seidel CL, Richards BF: A comparison of in-class learner engagement across lecture, problembased learning, and team learning using the STROBE classroom observation tool. Teach Learn Med 2005, 17(2):112-118.

16. Seidel CL, Richards BF: Application of team learning in a medical physiology course. Acad Med 2001, 76:533-534.

17. Dunaway GA: Adaption of team learning to an introductory graduate pharmacology course. Teach Learn Med 2005, 17:56-62.

18. Zgheib NK, Simaan JA, Sabra R: Using team-based learning to teach pharmacology to second year medical students improves student performance. Med Teacher 2010, 32:130-135.

19. Abdelkhalek N, Hussein A, Gibbs T, Hamdy H: Using team-based learning to prepare medical students for future problem-based learning. Med Teacher 2010, 32:123-129.

20. Shankar N, Roopa R: Evaluation of a modified team based learning method for teaching general embryology to 1 st year medical graduate students. Indian J Med Sci 2009, 63(1):4-12.

21. Chung EK, Rhee JAE, Baik YH, Oh-Sun A: The effect of team-based learning in medical ethics education. Med Teacher 2009, 31(11):1013-1017.

22. Davidson LK: A 3-year experience implementing blended TBL: active instructional methods can shift student attitudes to learning. Med Teacher 2011, 33:750-753.

23. Thompson BM, Schneider VF, Haidet P, Levine RE, McMahon KK, Perkowski LC, Richards BF: Team-based learning at ten medical schools: two years later. Med Educ 2007, 41(3):250-257.

24. Shellenberger $\mathrm{S}$, Seale JP, Harris DL, Johnson JA, Dodrill CL, Velasquez MM: Applying team-based learning in primary care residency programs to increase patient alcohol screenings and brief interventions. Acad Med 2009, 84(3):340-346.

25. Touchet BK, Coon KA: A pilot use of team-based learning in psychiatry resident psychodynamic psychotherapy education. Acad Psych 2005, 29(3):293-296

26. Khüne-Eversmann $L$, Eversmann T, Fischer MR: Team- and case-based learning to activate participants and enhance knowledge: an evaluation of seminars in Germany. J Contin Educ Health Prof 2008, 28:165-171

27. Team-Based Learning Collaborative: www.teambasedlearning.org.

28. Baylor College of Medicine: Classroom Engagement survey. Houston, Texas: Team learning in medical education workshop handbook; 2001.

29. Baylor College of Medicine: Value of Teams survey. Houston, Texas: Team learning in medical education workshop handbook; 2001. 
30. Vasan NS, DeFouw DO, Compton S: A survey of student perceptions of team-based learning in anatomy curriculum: Favorable views unrelated to grades. Anat Sci Educ 2009, 2:150-155.

31. Davis D, Thomson O'Brien MA, Freemantle N, Wolf FM, Mazmanian P,

Taylor-Vaisey A: Do conferences, workshops, rounds, and other traditional continuing education activities change physician behavior or health care outcomes? JAMA 1999, 282(9):867-874.

32. Mazmanian PE, Davis DA: Continuing medical education and the physician as a learner: guide to the evidence. JAMA 2002, 288(9):1057-1060

33. Svirko E, Mellanby J: Attitudes to e-learning, learning style and achievement in learning neuroanatomy by medical students. Med Teacher 2008, 30:219-227.

34. Erk S, Kiefer K, Grothe J, Wunderlich AP, Spitzer M, Waltera H: Emotional context modulates subsequent memory effect. Neurolmage 2003, 18:439-447.

35. Gray JR, Braver TS, Raichle ME: Integration of emotion and cognition in the lateral prefrontal cortex. Proc Nat Acad Sci 2002, 99(6):4115-4120,

36. New Ways of Working: http://www.dh.gov.uk/en/Publicationsandstatistics/ Publications/PublicationsPolicyAndGuidance/DH_074490.

37. Reimschisel T, Green S: Utilization of a modified Team-Based Learning format in the Pediatric Residency Core Curriculum, Poster presentation at 11th Annual Team-Based Learning Collaborative Meeting. 2012.

Cite this article as: McMullen et al:: Team-based learning for psychiatry residents: a mixed methods study. BMC Medical Education 2013 13:124.

\section{Submit your next manuscript to BioMed Central and take full advantage of:}

- Convenient online submission

- Thorough peer review

- No space constraints or color figure charges

- Immediate publication on acceptance

- Inclusion in PubMed, CAS, Scopus and Google Scholar

- Research which is freely available for redistribution 